\title{
Occurrence of a Strain of Texas pepper virus in Tabasco and Habanero Pepper in Costa Rica
}

Pongtharin Lotrakul, Rodrigo A. Valverde, Rodolfo De La Torre, and Jeonggu Sim, Department of Plant Pathology and Crop Physiology, Louisiana Agricultural Experiment Station, Louisiana State University Agricultural Center, Baton Rouge 70803; and Alvaro Gomez, Inversiones Agroindustriales PEMACA S.A., Apartado 11617050, Cartago, Costa Rica

\begin{abstract}
Lotrakul, P., Valverde, R. A., De La Torre, R., Sim, J., and Gomez, A. 2000. Occurrence of a strain of Texas pepper virus in Tabasco and Habanero pepper in Costa Rica. Plant Dis. 84:168172 .

A viral disease causing severe leaf malformation and yellow mottle on Tabasco (Capsicum frutescens) and Habanero (C. chinense) pepper plants was observed in 1997 on farms in southwestern Costa Rica. Whiteflies (Bemisia tabaci) were present on affected farms and transmitted the putative virus. Total DNA was extracted from a whitefly-transmitted isolate, and polymerase chain reaction (PCR) was performed using degenerate primers. The expected PCR product (550 bp) was obtained, suggesting the presence of a geminivirus. This was confirmed by Southern analysis using a geminivirus-specific probe. The virus was mechanically transmitted from pepper to pepper. Electron microscopy of ultrathin sections from infected Tabasco pepper plants revealed fibrillar rings and viruslike particles in the nucleus of the vascular parenchyma cells. The sequence of DNA A was obtained from three overlapping PCR fragments amplified using three pairs of degenerate primers; PAL1v1978/PAR1c496, PCRc1/AV494, and PCRv181/ AC1048. The complete sequence of DNA A of this begomovirus consisted of 2,619 bp (GenBank accession number: AF149227) containing four open reading frames (ORF). The nucleotide sequence of the virus was 92.3\% identical to DNA A of the Tamaulipas strain of Texas pepper virus (TPV-TAM). Phylogenetic analyses using AC1 and AV1 nucleotide sequences also indicated a close relationship between this virus and TPV. Based on the biological characteristics, the high percentage of nucleotide and derived amino acid sequence identities, and phylogenetic analyses, we concluded that this virus is a distinct strain of TPV, and designated it as the Costa Rica strain. This is the first report of TPV in Costa Rica.
\end{abstract}

Members of the family Geminiviridae are a group of plant viruses that have small twin-isometric particles containing singlestranded DNA genome (12). This family can be classified into three genera based on their hosts, insect vector, and genome organization (5). Members of the genus $\mathrm{Be}$ gomovirus contain mono- or bipartite genomes, infect dicot plants, and can be transmitted by whitefly (Bemisia tabaci). Two important pepper-infecting begomoviruses from North America, Texas pepper virus (TPV) and Pepper huasteco virus (PHV) have been reported $(2,8,10,12)$. During the last decade, these viruses have caused important losses in pepper crops in Texas and in Mexico (12).

Corresponding author: Rodrigo A. Valverde E-mail: rvalverde@agctr.lsu.edu

Approved for publication by the Director of the Louisiana Agricultural Experiment Station as manuscript 99-38-0322.

GenBank accession number for nucleotide sequence: AF149227.

Accepted for publication 9 November 1999.

Publication no. D-1999-1217-01R

(c) 2000 The American Phytopathological Society
A viral disease causing severe leaf malformation and yellow mottle on Tabasco (Capsicum frutescens) and Habanero ( $C$. chinense) pepper plants was observed in 1997 on farms in Perez Zeledon County, Costa Rica. The percentage of infected plants varied among farms (25 to $75 \%$ ). Whiteflies (Bemisia tabaci) were present in affected fields and transmitted the putative virus in preliminary experiments. A preliminary polymerase chain reaction (PCR) test using degenerate primers AV494/AC1048, which amplify the core region of the coat protein of many begomoviruses (13), and Southern hybridization using DNA A of the Dominican Republic isolate of Tomato yellow leaf curl virus (TYLCV-DR) as a specific probe indicated this putative virus was a begomovirus. It was characterized and its phylogenetic relationships with other begomoviruses were investigated.

\section{MATERIALS AND METHODS}

Virus isolates. Leaf samples from Tabasco and Habanero peppers showing severe leaf malformation and yellow mottle symptoms (Fig. 1) were collected from three farms in the southwest region of Costa Rica (Perez Zeledon County). Mechanical inoculation to healthy Tabasco plants was conducted. Leaf sap (in 0.002 $\mathrm{M}$ sodium phosphate buffer, $\mathrm{pH}$ 7.2) was inoculated onto Carborundum-dusted leaves of healthy pepper seedlings ( 3 week old). Inoculated plants that developed symptoms were used for whitefly transmission experiments. A virus isolate from an individual whitefly transmission was selected and used for all successive experiments. Other begomoviruses used in this study were Bean golden mosaic virus from Florida and Sweetpotato leaf curl virus from Louisiana.

Whitefly transmissions. Colonies of the sweetpotato whitefly (Bemisia tabaci biotype B) were reared on caged cotton plants in the laboratory. Individual whiteflies or groups of 10 were used for transmission experiments from infected Tabasco pepper to healthy Tabasco seedlings ( 3 week old). Whiteflies were caged with infected plants for $48 \mathrm{~h}$. Viruliferous whiteflies were transferred to caged healthy plants using a glass tube. The transmission period was $48 \mathrm{~h}$. All transmission tests were conducted in the laboratory. After the transmission test, plants were sprayed with imidacloprid (Merit) and transferred to the greenhouse (under natural light and an average temperature of $26^{\circ} \mathrm{C}$ ). Plants were evaluated for visual symptoms 2 to 3 weeks later. Symptomless plants and some showing symptoms were tested for the presence of a begomovirus by PCR or Southern hybridization.

Host reaction. To determine the host range of the virus, mechanical and graft inoculations were conducted on at least three plants of the same species. Leaf sap from infected Tabasco pepper was used as the inoculum for mechanical inoculations. Graft transmissions were conducted using infected Tabasco pepper as the scion. The following pepper genotypes with resistance to potyviruses (1) were graft-inoculated: Capsicum annuum (Yolo Wonder, VR-4, Avelar, Agronomico, and Jaloro), C. chinense ( PI 152225 and PI 159236), and $C$. frutescens (Tabasco, Greenleaf Tabasco, and LP-1). Other plant species inoculated were Nicotiana benthamiana, $N$. clevelandii, Datura metel, D. stramonium, Physalis ixocarpa, and Lycopersicon esculentum cv. Rutgers. Test plants were examined for symptoms 2 to 3 weeks after inoculations. PCR was performed on all plant species tested. 
Electron microscopy. Tissue samples (veins with adjacent mesophyll) from healthy and infected Tabasco pepper were fixed for electron microscopy as previously described (7).

DNA extraction and Southern hybridization. Total DNA from tissues of field-collected Tabasco and Habanero pepper showing viruslike symptoms was extracted either by a protocol described by Dellaporta et al. (4) or Plant DNAzol Reagent procedures (Life Technologies, Inc., Grand Island, NY). Extracted DNA was separated by electrophoresis and stained with ethidium bromide. Southern hybridization was conducted using Amersham's ECL kit (Arlington Heights, IL) following the manufacturer's procedures. Alternatively, the DIG High Prime Labeling and Detection Kit (Boehringer Mannheim, Indianapolis, IN) was used in some experiments. TYLCV-DR and DNA A and B of Bean golden mosaic virus from Guatemala (BGMV-GA) were used as geminivirus-specific probes. Hybridization was carried out under conditions previously described (7). The entire DNA A sequence of the pepper-infecting geminivirus was obtained from three overlapping PCR fragments amplified by three pairs of degenerate primers: AV494 (13)/PCRc1 (9), PAL1v1978/ PAR1c496 (9), and PCRv181 (9)/ AC1048 (13). PCR was performed in an Amplitron II thermocycler (Thermolyne, Dubuque, IA) as described (7). The PCR products were recovered from agarose gel using the Ultraclean15 DNA purification kit (MO Bio Laboratories Inc., Solana Beach, CA). Purified PCR products

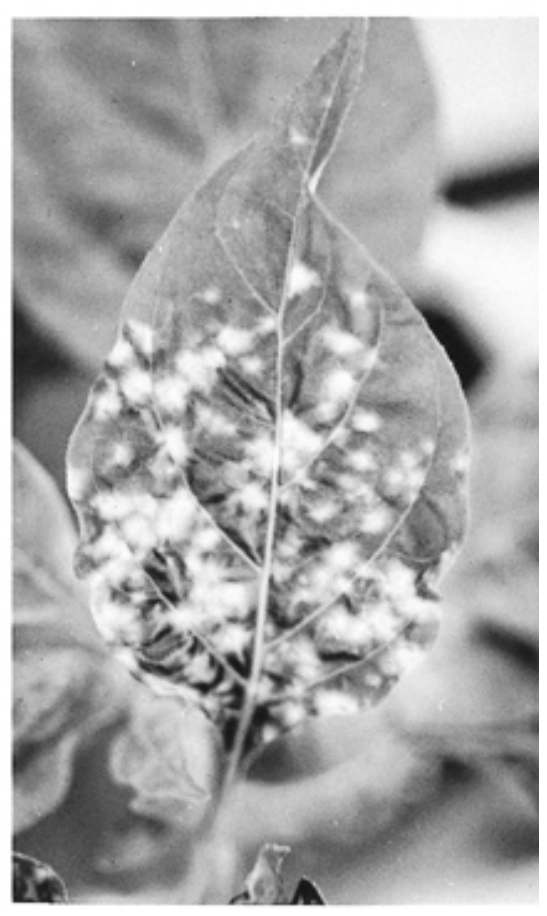

Fig. 1. Leaf malformation and yellow mottle symptoms on Tabasco pepper infected with Texas pepper virus from Costa Rica. were cloned into pBluescript II SK (+) (Stratagene, La Jolla, CA). Restriction endonucleases and T4 DNA polymerase were used as recommended by the manu- facturers. Recombinant plasmids were then transformed into competent cells of Escherichia coli strain DH5 $\infty$. Recombinant plasmids containing the amplified DNA A

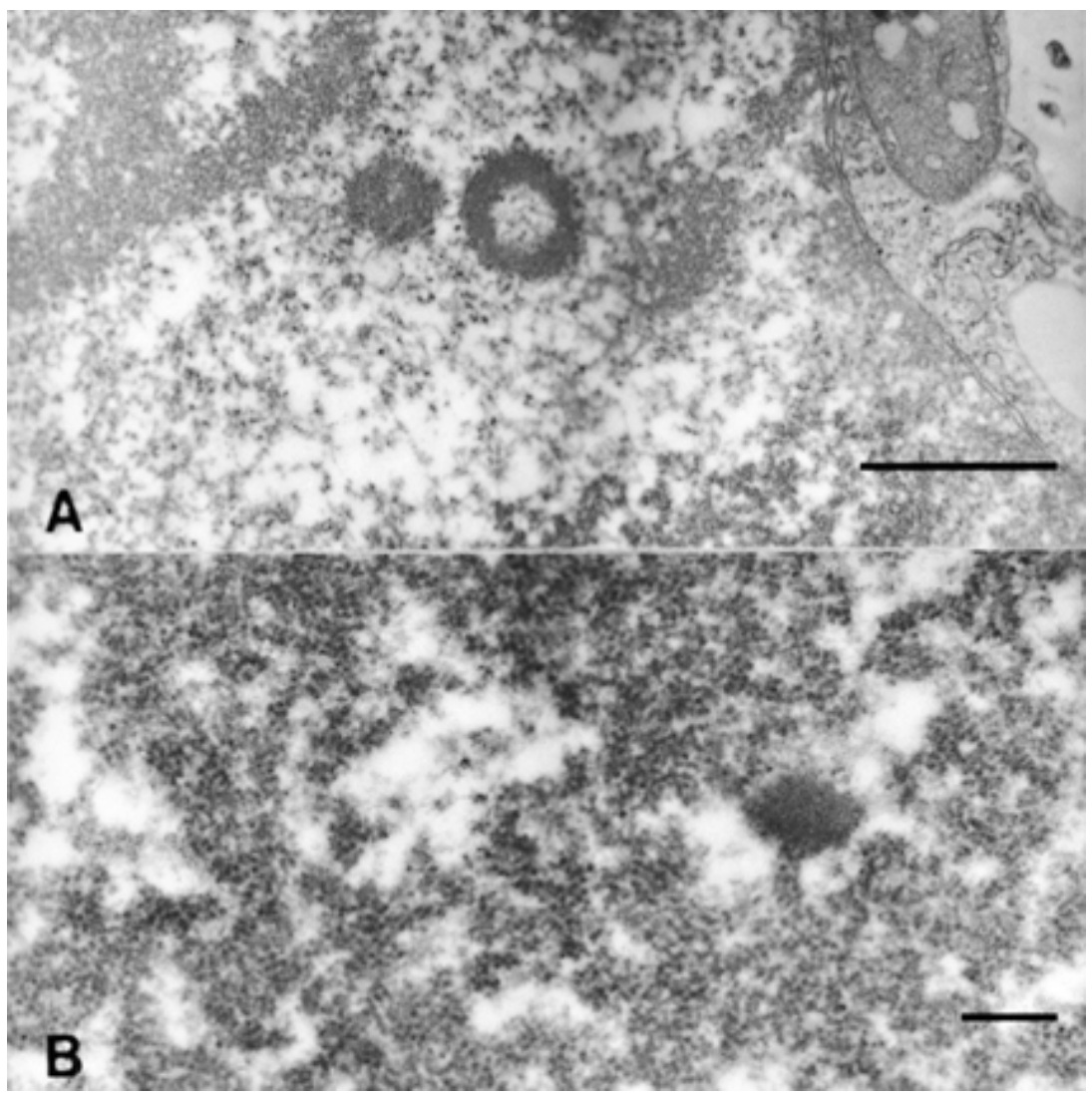

Fig. 2. Ultrathin sections of leaves of Capsicum frutescens cv. Tabasco infected with the Costa Rica isolate of Texas pepper virus: (A) nucleus of parenchyma cell showing fibrillar rings, (B) aggregates of viruslike particles. Scale bars (A) $500 \mathrm{~nm}$ and (B) $100 \mathrm{~nm}$.

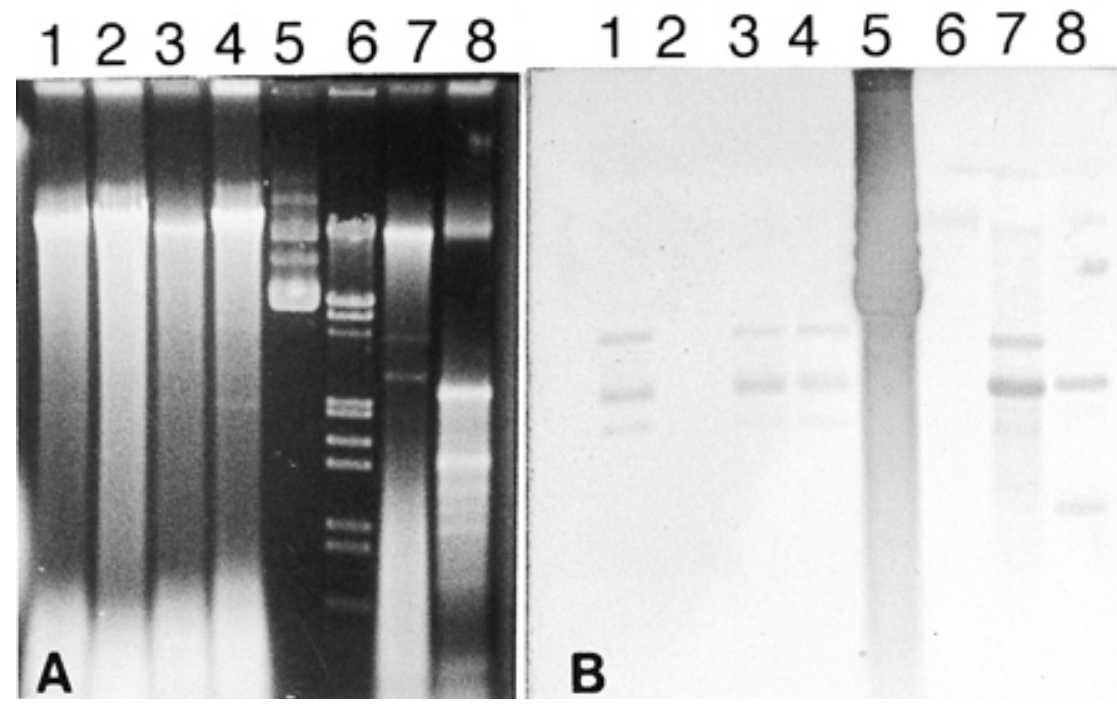

Fig. 3. Detection of Texas pepper virus from symptomatic Tabasco and Habanero pepper plants using a probe prepared with the DNA recombinant plasmid of an isolate of Tomato yellow leaf curl virus from the Dominican Republic (TYLCV-DR). (A and B) Agarose gel (1.2\%) containing DNA from: lane 1, Habanero pepper from Perez Zeledon (PZ) sample C ; lane 2, Habanero pepper PZ sample A; lane 3, Tabasco pepper PZ sample D; lane 4, Tabasco PZ-J; lane 5, TYLCV-DR; lane 6, Lambda (EcoRI/Hind III digested); lane 7, a Florida isolate of Bean golden mosaic virus; and lane 8, a Louisiana isolate of Sweetpotato leaf curl virus. Total DNA was extracted from $1.0 \mathrm{~g}$ of tissue and the equivalent to $0.025 \mathrm{~g}$ loaded in the gel. (A) Ethidium bromide-stained gel. (B) Southern blot DNA hybridization of the gel. DNA labeling and detection was performed using DIG High Prime Labeling and Detection Kit (Boehringer Mannheim). 
fragment of the virus were then screened by Southern hybridization.

Sequence determination. The nucleotide sequences were determined by automated sequence analysis at the DNA Sequencing Core Laboratory, University of Florida, Gainesville (ABI337 DNA Sequencer; Perkin Elmer, Foster City, CA). At least three replicate PCR-clones were sequenced to minimize any error caused by Taq polymerase. Restriction sites were analyzed using DNAid+ program (F. Daedel, Ecole Polytechnique, Palaiseau, France), and the predicted sites were confirmed by digestion with their specific restriction enzymes. Open reading frames (ORF) and predicted amino acid sequences were determined using the Translate program (ExPASy molecular biology server, Swiss Institute of Bioinformatics).

Sequence comparisons and phylogenetic analyses. Obtained nucleotide and predicted amino acid sequences were compared with those of the DNA A of other whitefly-transmitted geminiviruses in the GenBank. Multiple sequence alignment was carried out using version 1.7 of the CLUSTAL W program (11). Percent identities and similarities between aligned nucleotide and derived amino acid sequences were determined using the equation: $100 \times$ sum of matching residues $\div$ [length - gap residues (sequence 1) - gap residues (sequence 2)] (3). Phylogenetic analyses using parsimony and bootstrap option (100 replicates) were performed with version $3.5 \mathrm{c}$ of the Phylogeny Inference Package (PHYLIP) developed and distributed by J.
Felsenstein (Department of Genetics, University of Washington, Seattle). Geminivirus sequences used in sequence and phylogenetic analyses were from GenBank database under the following accession numbers: BGMV-GA (M91604), Beet curly top virus (BCTV) (U56975), Cabbage leaf curl virus (CaLCV) (U65529), Pepper huasteco virus (PHV) (X70418), Potato yellow mosaic virus (PYMV) from Trinidad and Tobago (AF039031), Sida golden mosaic virus (SiGMV) from Florida (AF049336), the Tamaulipas strain of TPV (TPV-TAM) (U57457), and the Chiapas strain of TPV (TPV-CPS) (AF077745 and AF077025).

\section{RESULTS}

Whitefly transmissions. Results of two whitefly transmission experiments (using individual whiteflies or groups of 10) confirmed our preliminary study that this putative virus was whitefly-transmitted. Individual Bemisia tabaci biotype B vectored the virus at a rate of $8 \%(2 / 25)$, while groups of 10 whiteflies transmitted the virus at a rate of $69 \%$ (20/29). Severe yellow mottle and leaf malformation symptoms appeared 2 weeks after Tabasco pepper seedlings were exposed to viruliferous whiteflies. Pepper seedlings caged with whiteflies that fed on healthy plants remained symptomless. PCR tests confirmed the presence of a begomovirus in plants showing symptoms, but not in symptomless plants.

Host reaction. This putative pepper-infecting begomovirus was readily mechani-

Table 1. Percent nucleotide identities (open reading frames AV1, AC1, AC2, and AC3) of the Costa Rica strain of Texas pepper virus with those of selected New World begomoviruses

\begin{tabular}{lllll}
\hline Virus & AV1 & AC1 & AC2 & AC3 \\
\hline Texas pepper virus -Tamaulipas & 93.4 & 91.8 & 93.3 & 93.2 \\
Cabbage leaf curl virus -Florida & 86.4 & 78.9 & 85.4 & 83.2 \\
Potato yellow mosaic virus -Trinidad & 81.5 & 66.7 & 75.6 & 77.9 \\
Bean golden mosaic virus -Guatemala & 81.6 & 65.0 & 79.2 & 80.9 \\
Sida golden mosaic virus -Florida & 81.8 & 64.5 & 73.1 & 74.7 \\
Pepper huasteco virus -Mexico & 80.0 & 60.8 & 67.2 & 73.2 \\
\hline
\end{tabular}

cally transmitted from pepper to pepper. Graft inoculations to $C$. annuum (Yolo Wonder, VR-4, Avelar, Agronomico, and Jaloro), C. chinense ( PI 152225 and PI 159236), and C. frutescens (Tabasco, Greenleaf Tabasco, and LP-1) with infected Tabasco scions resulted in successful infections. All Capsicum species reacted with severe mottle and leaf malformation. Other hosts that were successfully graft-inoculated were $N$. benthamiana, $N$. clevelandii, D. metel, and $D$. stramonium. However, attempts to graftinfect this virus to $P$. ixocarpa and $L$. esculentum cv. Rutgers failed.

Electron microscopy. Electron microscopic observations of ultrathin sections from infected Tabasco pepper plants revealed fibrillar rings in the nucleus of the vascular parenchyma cells, which is typical of geminivirus-infecting plants (Fig. 2A). Geminivirus-like particles also were present within the nuclei of infected cells (Fig. 2B).

Molecular hybridization. DNA probes prepared with TYLCV-DR genome hybridized with a 2.6-kb DNA and other virus-associated DNAs present in total DNA extracted from the infected pepper, but not with that of healthy plants (Fig. 3). Under high stringency condition, similar results were obtained when each DNA A and B of BGMV-GA was separately used as a probe (data not shown). These results indicate that this pepper-infecting virus might be a bipartite begomovirus.

Genome organization. The complete DNA A sequence of the pepper-infecting begomovirus from Costa Rica was assembled using three overlapping PCR clones. DNA A consisted of 2,619 bp (GenBank accession number AF149227). Computerassisted analysis of the sequence revealed four ORF, designated AV1, AC1, AC2, and AC3, which is typical of the DNA A of a bipartite begomovirus. ORF were located on both virion and complementary sense strands.

Preliminary sequence comparison between DNA A of this pepper-infecting

\begin{tabular}{|c|c|}
\hline TPV-CPS & САTTTTTGCAAATATTGCGTAGGACTCCAGC \\
\hline TPV-TAM & CATTTTTGCAAATATGGTGTAGGACTCCA \\
\hline \multirow{2}{*}{ TPV-CR } & САTTTTTGCAAATATGTTGTAGGACTCCA \\
\hline & -ー-ー-ー-ー \\
\hline TPV-CPS & GTGGAGTCCTGGAGTCCCTTATATACATA \\
\hline TPV-TAM & GTGGAGTCCTGGAGTCCCTTATATACATA \\
\hline \multirow[t]{2}{*}{ TPV-CR } & GTGGAGTCCTGGAGTCCCTTAAATACTAG \\
\hline & $---------------\quad \ldots \ldots$ \\
\hline TPV-CPS & GGCCATCCTATAATATTACTGGATGGCCG \\
\hline TPV-TAM & GGCCATCCTATAATATTACCGGATGGCCG \\
\hline TPV-CR & 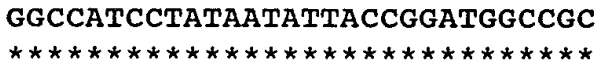 \\
\hline
\end{tabular}

Fig. 4. Sequence alignment of the common region of three Texas pepper virus isolates: Costa Rica (TPV-CR), Chiapas (CPS), and Tamaulipas (TAM). All sequences start from the first codon of the AC1 open reading frame and end at the $3^{\prime}$-end of the stem-loop motif. Underlined bases represent the iterative elements. Dotted bases represent TATA box, and bases with asterisks represent the conserved stem-loop motif. 
begomovirus and those of other begomoviruses showed high nucleotide sequence identity $(92.3 \%)$ to TPV-TAM (data not shown). When ORF on the DNA A of the virus were aligned with their counterparts from other selected New World begomoviruses, more than $90 \%$ nucleotide sequence identity was detected with all ORF of TPV-TAM, while identity with other begomoviruses ranged from $86.4 \%$ to less than $60.8 \%$ (Table 1). Therefore, this pepper-infecting begomovirus was designated as the Costa Rica strain of TPV (TPV-CR). Derived amino acid sequence comparisons between homologous ORF of TPV-CR and TPV-TAM revealed 89.4 to 97.2\% amino acid identity (97.2, 92.2, 89.9, and $89.4 \%$ for $\mathrm{AV} 1$ and $\mathrm{AC} 1$ to $\mathrm{AC} 3$, respectively). The common region sequences (150 bp from start codon of the AC1 ORF to the $3^{\prime}$ end of the stem-loop motif) of TPV-CR, TPV-CPS, and TPVTAM were also compared. Up to $89 \%$ nucleotide sequence identity was detected with identical sequence and arrangement of the iterative elements (GGACTCCA) (8) (Fig. 4).

Phylogenetic analyses. Relationships between TPV-CR and other whitefly- transmitted geminiviruses were analyzed based on AV1 and AC1 nucleotide sequences. Both ORF analyzed indicated a close relationship with TPV-TAM (Fig. 5).

\section{DISCUSSION}

Based on the similar biological and molecular characteristics and close phylogenetic relationships between this pepperinfecting virus from Costa Rica and TPV isolates from Mexico, we concluded that the virus is a distinct strain of TPV, which we designated TPV-CR.

Although only the DNA A sequence of TPV-CR was described in this paper, it is likely that DNA B of TPV-CR exists. This is supported by the genome organization of DNA A (typical of a bipartite begomovirus) and the positive results of Southern hybridizations (under high stringency condition) using DNA B of BGMV as probe. Attempts to amplify partial DNA B sequence using degenerate primers prBV1855 and prBC656 (6) failed (data not shown). This might be due to the differences in DNA sequence between TPV-CR and other New World begomoviruses.

Although TPV-CR is similar to TPVTAM, it has some distinct differences (10).
TPV-TAM can induce mosaic, leaf curling, and stunting symptoms on tomato $(L$. es culentum cv. 3, Sunlight, and 743-T) and mosaic, distortion, and stunting symptoms on Physalis wrightii (10). Repeated attempts to infect tomato (L. esculentum cv. Rutgers) and $P$. ixocarpa with TPV-CR failed. This might be due to the different Rep protein sequences between TPV-CR and TPV-TAM. The Rep protein has been suggested as the specific host-activation factor (5).

Although this is the first report of TPV in Costa Rica, TPV may be widespread in Central America. We analyzed Tabasco pepper samples from farms located near three cities in Honduras (Tocoa, Santa Rita, and El Progreso) using degenerate primers AV494/AC1048 (13) and found positive samples in all three locations. Sequence comparisons of the core coat protein region revealed nearly identical nucleotide sequence $(98 \%)$ between the begomovirus from these three samples and TPV-TAM (P. Lotrakul and R. A. Valverde, unpublished). From their geographical distribution and nucleotide sequence identities, it might be possible that several strains of TPV have diverged from a com-
A

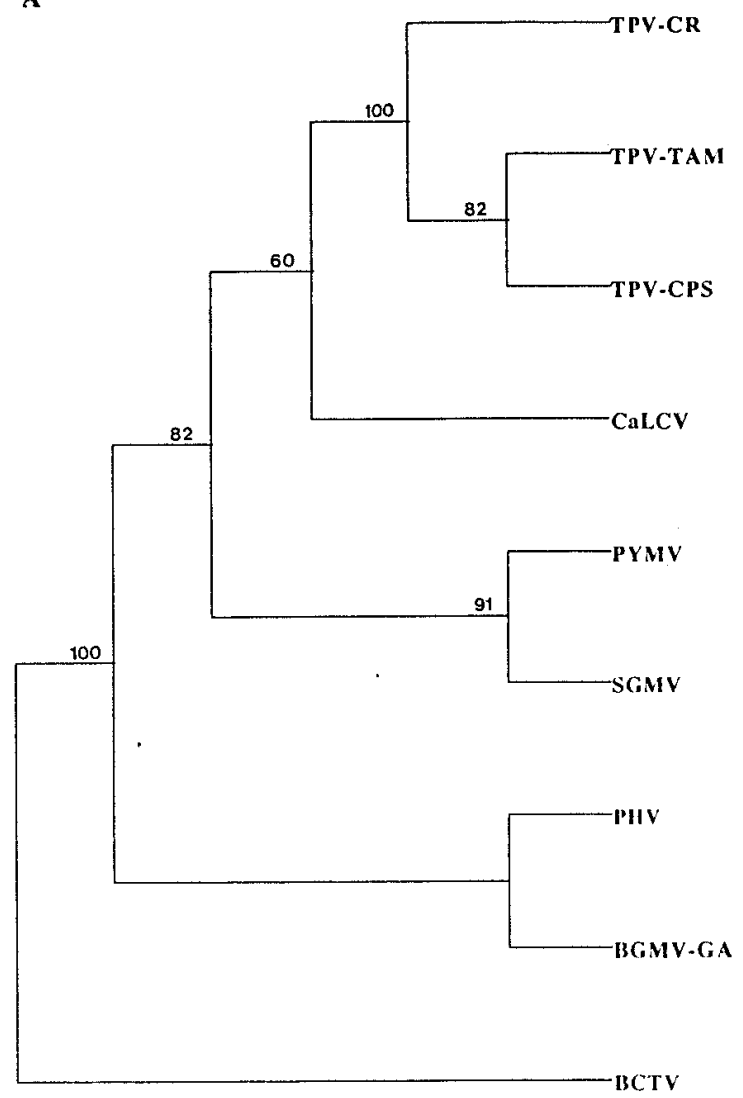

B

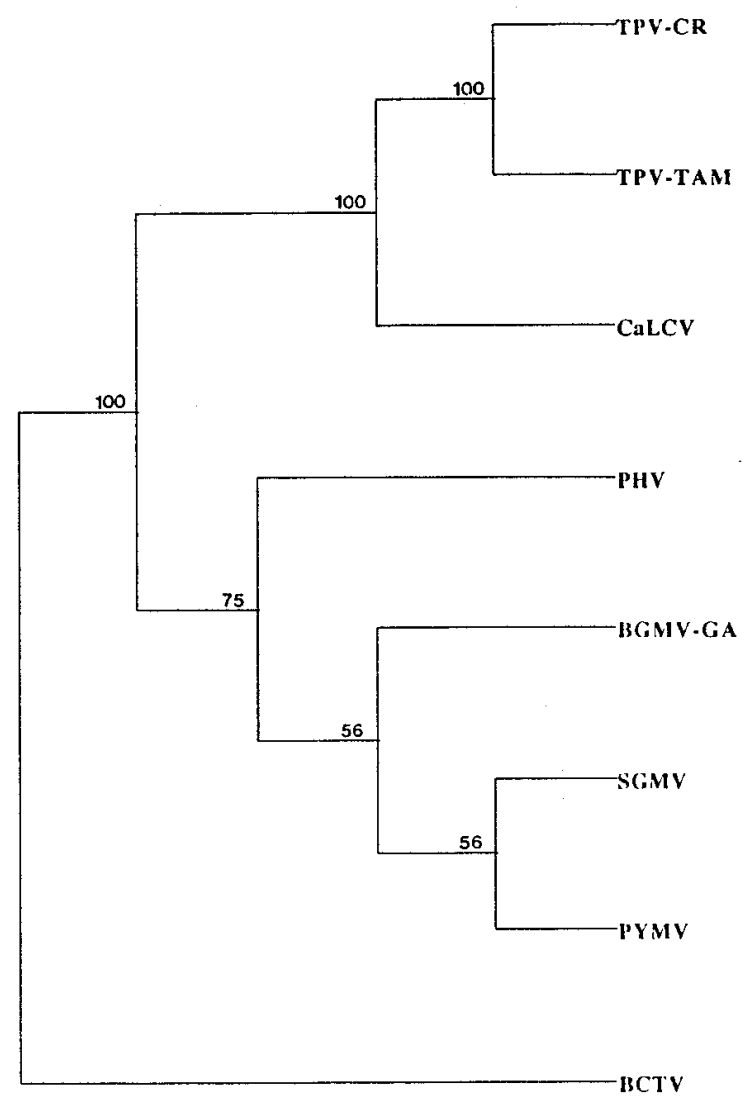

Fig. 5. Phylogenetic tree showing the relationship of Texas pepper virus-Costa Rica (TPV-CR) with other begomoviruses from the New World based on the multiple sequence alignment of (A) AV1 and (B) AC1 nucleotide sequences using programs in CLUSTAL W package version 1.7. These trees were constructed using Seqboot, Propars, and Consense programs in the PHYLIP package version 3.5c. Analysis of the 100 trees constructed resulted in only one most parsimonious tree. Along each internal branch bootstrap number in which the given branch is supported is shown with $50 \%$ majority-rule. Vertical and horizontal branch lengths are arbitrary. TPV-Tamaulipas (TAM); TPV-Chiapas (CPS); Cabbage leaf curl virus (CaLCV); Potato yellow mosaic virus (PYMV); Sida golden mosaic virus (SiGMV); Pepper huasteco virus (PHV); Bean golden mosaic virus-Guatemala (BGMV-GA); and Beet curly top virus (BCTV), a curtovirus. 
mon ancestor. However, more comparative biological and molecular characterization of TPV from different geographical areas needs to be conducted.

The presence of TPV-CR is a new threat for pepper farmers of Central America. Incidences as high as $75 \%$ were found in some fields in southwest Costa Rica. This could be due to the worldwide outbreak of whitefly populations (2). This is the first report of natural infection of a begomovirus in the economically important Tabasco and Habanero pepper cultivars. Unfortunately, pepper cultivars with high levels of resistance to potyviruses (1), were susceptible to TPV-CR. A better understanding of the epidemiology of TPV-CR and its related strain(s) is needed for developing effective management of this disease.

\section{ACKNOWLEDGMENTS}

We thank K. S. Kim (University of Arkansas) for advice in electron microscopy; R. L. Gilbertson (University of California, Davis) for providing geminivirus clones, and J. K. Brown for sequence comparison of the core coat protein region.
LITERATURE CITED

1. Ariyaratne, I., Hobbs, H. A., Valverde, R. A., Black, L. L., and Dufresne, D. J. 1996. Resistance of Capsicum spp. genotypes to tobacco etch potyvirus isolates from the Western Hemisphere. Plant Dis. 80:12571261.

2. Brown, J. K., and Bird, J. 1992. Whiteflytransmitted geminiviruses and associated disorders in the Americas and the Caribbean Basin. Plant Dis. 76:220-225.

3. Brown, J. K., Ostrow, K. M., Idris, A. M., and Stenger, D. C. 1999. Biotic, molecular, and phylogenetic characterization of bean calico mosaic virus, a distinct Begomovirus species with affiliation in the squash leaf curl virus cluster. Phytopathology 89:273-280.

4. Dellaporta, S. L., Wood, J., and Hicks, J. B. 1983. A plant DNA minipreparation: Version II. Plant Mol. Biol. Rep. 1:19-21.

5. Hanley-Bowdoin, L., Settlage, S. B., Orozco, B. M., Nagar, S., and Robertson, D. 1999. Geminiviruses: Models for plant DNA replication, transcription, and cell cycle regulation. Critic. Rev. Plant Sci. 18:71-106.

6. Idris, A. M., and Brown, J. K. 1998. Sinaloa tomato leaf curl geminivirus: Biological and molecular evidence for a new subgroup III virus. Phytopathology 88:648-657.

7. Lotrakul, P., Valverde, R. A., Clark, C. A., Sim, J., and De La Torre, R. 1998. Detection of a geminivirus infecting sweet potato in the
United States. Plant Dis. 82:1253-1257.

8. Paximadis, M., Idris, A. M., Torres-Jreez, I., Vllarreal, A., Rey, M. E. C., and Brown, J. K 1999. Characterization of tobacco geminiviruses in the old and new world. Arch. Virol. 144:703-717.

9. Rojas, M. R., Gilbertson, R. L., Russell, D. R., and Maxwell, D. P. 1993. Use of degenerate primers in the polymerase chain reaction to detect whitefly-transmitted geminiviruses. Plant Dis. 77:340-347.

10. Stenger, D. C., Duffus, J. E., and Villalon, B. 1990. Biological and genomic properties of a geminivirus isolated from pepper. Phytopathology 80:704-709.

11. Thompson, J. D., Higgins, D. G., and Gibson, T. J. 1994. Clustal W: Improving the sensitivity of progressive multiple sequence alignment through sequence weighting, positionsspecific gap penalties, and weight matrix choice. Nucleic Acids Res. 22:4673-4680.

12. Torres-Pacheco, I., Garzon-Tiznado, J. A., Brown, J. K., Becerra-Flora, A., and RiveraBustamante, R. F. 1996. Detection and distribution of geminiviruses in Mexico and the southern United States. Phytopathology 86:1186-1192.

13. Wyatt, S. D., and Brown, J. K. 1996. Detection of subgroup III geminivirus isolates in leaf extracts by degenerate primers and polymerase chain reaction. Phytopathology 86:1288-1293. 